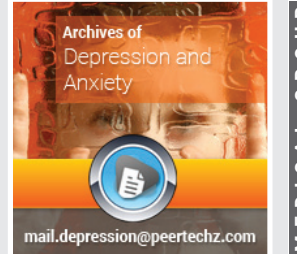

\title{
Amnesia: Definition, main models, classifications, neurobiological profiles and clinical treatments
}

Received: 04 April, 2020

Accepted: 26 June, 2020

Published: 27 June, 2020

*Corresponding author: Giulio Perrotta, Psychologist sp.ed Strategic Psychotherapist, Forensic Criminologist, Jurist sp.ing SSPL, Lecturer, Essayist, Italy E-mail: giuliosr1984@hotmail.it

https://www.peertechz.com

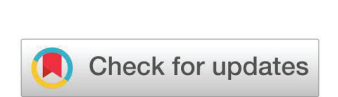

\author{
Giulio Perrotta* \\ Psychologist sp.ed Strategic Psychotherapist, Forensic Criminologist, Jurist sp.ing SSPL, Lecturer, \\ Essayist, Italy
}

\begin{abstract}
This work focuses on the theme of amnesia and in particular on the clinical, psychopathological and neurophysiological elements. It is evident that the resolution of the amnestic condition depends mainly on the clinical cause that originates it and therefore on its management and recovery. Amnesia is therefore a symptom of a more extensive pathological condition, which must be investigated and treated with the best possible techniques, except for the hypotheses of irreparable damage.
\end{abstract}

\section{Contents of the manuscript}

\section{Introduction and main models}

Memory is the ability to keep the information acquired by the system, so that it can be available and used for carrying out tasks to be performed. The recovery of the mnemonic data can occur in three ways:

a) "Free re-enactment": The subject tries to remember with a free search the detail concerned;

b) "Suggestive re-enactment": The subject tries to remember in the presence of a suggestion;

c) "Recognition": The subject tries to remember following a specific stimulus.

The re-enactment, according to the Rey's test, will follow a typical curve (serial position), so the first re-evoked words will be the last of the list (recency effect) and then the first of the list (primacy effect). These operations, however, do not always ensure the recovery of memory, since certain factors may have intervened favoring oblivion (curve of oblivion, Ebbinghaus, 1885), or the inability/impossibility of recovering the information sought, due to the flow of time, of emotional factors, of temporary or permanent physical pathologies, of internal or external interference, or of the removal mechanism.

\section{The main models are}

\section{1) Bartlett's constructivist theory (1932)}

The memory process is the product of a restructuring in which the subject uses active strategies for reconstructing the memory trace on the basis of comparison and integration with the information already present in memory, according to one's personal and emotional experience.

\section{2) Neisser's theory of reappearance (1967)}

Memories would be closed mental events, that is, finished copies of stored materials. This theorized registration mechanism integrates some functions previously identified by other authors, such as "schematization" (intended as the reduction of essential lines - Bartlett, 1932) and allows (in subsequent years) to other authors to identify other functions, then confirmed by scientific studies, such as:

a) "Integration", or incorporation by addition and compensation (Palmer, 1974);

b) "Abstraction", or substitution with a formula or symbols (Sachs, 1977);

c) "Selection", ie chosen on a utilitarian and convenience basis (Anderson, 1978); 
d) "Interpretation", or translation in terms of validity on a cognitive and practical level (Hasher, 1983).

\section{3) The serial theory of Atkinson and Shiffrin (1968-} 1971) $[1]$

The human mind is a calculator, a Human Information Processing (HIP). The model has three stages corresponding to three warehouses placed in series: the sensory register (Sperling, 1963), short-term memory and long-term memory. Therefore, the stimuli are first recorded through senseperceptual processes (for sounds the ecoic memory intervenes, for the visual stimuli the iconic memory intervenes); at this point the information first accesses the "short term" and then the "long term". Hence "serial", because they are "placed in series". In general, the stages of the mnestic act are four: a) acquisition; b) coding; c) maintenance; d) recovery of information.

Sperling, compared to the first warehouse, tried to evaluate how many visual elements could be seen in a short interval of time, using a "full report procedure". He presented the subjects with a $3 \times 3$ table, with three rows and three columns, for a total of nine squares within which there was a letter of the alphabet. He showed the chart for 50ms, then asked the subjects how many letters they could remember. The subjects were able to name only four or five, but reported that they had "seen" all nine. Sperling concluded, therefore, that in a short time you could see an entire image, but you could not keep it long enough to repeat it.

The second warehouse consists of the Short-Term Memory, with limited capacity, where the information remains for a short period, similar to about 30s. The capacity was quantified by the Ebbinghaus "span of digits" experiment, which observed that after listening to a list of syllables, it was possible to remember an average of seven, and then further deepened by Miller, according to which the Short Term Memory can hold from five to nine digits: he defined this quantity as "the magic number seven", precisely because on average the contents retained were "7+/- 2" and were to be understood not as single elements, but also as chunks, that is couples, triads or groupings of elements. The recovery speed depends on the number of information taking into account the extent and speed of information itself. This was also confirmed by an experiment by Sternberg, which proposed groups of subjects with lists of figures (from one to six) and then a check digit. The subjects had to say whether the check digit was contained in the previously reported list of digits. If the previous list was short, recognition occurred faster. The contents can pass from the sensorial memory to the short-term one if they are repeated, that is, if they are repeated several times.

The third warehouse is the Long-Term Memory, with capacity and extended duration, perhaps unlimited, since the information contained probably never disappears, although they may become more difficult to access. Two different types of information are distinguished within it: declarative information, consisting of explicit propositions, thoughts and memories, and procedural information, consisting of methods of performing an action (riding a bicycle, driving a car, etc.). Within the Long-Term Memory, the information is distributed in the form of a network, with numerous nodes: each information activates another information connected to it and propagates until the entire network is activated. LongTerm Memory has several warehouses, according to Tulving (1972):

\section{Those concerning the declarative (or explicit) memory}

- Semantic or taxonomic memory: knowledge concerning concepts, words, reciprocal relationships and meanings (e.g. the formula of water is $\mathrm{H} 2 \mathrm{O}$ );

- Episodic or chronological memory: it concerns events, actions, experiences. In this category, we distinguish between the episodic prospective and the retrospective episode: in the first case, we are dealing with the memory linked to the planned actions, that is, the set of skills that allow you to perform actions planned in the future (ie remember to remember), divided into "time-bases" (ie remembering to do something) and "event-bases" (ie remembering to carry out an activity before an action); in the second case, we are dealing with actions learned by the subject in a past time;

- Autobiographical memory: concerns personal life events (semantic aspects) and awareness of relationships (episodic aspects).

\section{Those concerning the non-declarative (or implicit) memory}

- Procedural memory: concerns the way of doing things and carrying out tasks and operations;

- Learned conditions;

- Priming phenomenon, or the facilitation in the process of a stimulus that derives from having previously experienced.

\section{Recent neuropsychology studies have shown that}

1) with reference to the short-term memorandum:

a) The memory remains vivid for about twenty seconds;

b) The quantity of information that can be stored is five to nine, with an average of seven;

c) Its operation is strongly linked to the level of attention and vigilance;

d) Is structured as a working memory;

e) uses a sensorial and perceptual coding and information maintenance and processing processes.

2) In reference to the Long-Term Memory

a) The memory remains stored for a very long time;

b) The quantity of information that can be stored is potentially infinite; 
c) Iits operation is strongly linked to the level of stability of the memory system;

d) Is structured as a storage container;

e) Uses semantic and associative coding.

3) The parallel theory (Shallice, 1986)

In contrast to the aforementioned serial type theory, this calls into question the whole scheme, showing that the information arrives at the long-term warehouse without going through the short-term one.

\section{4) The depth of coding theory by Craik \& Lockhart [2]}

They theorized the phenomena of storage and recovery, suggesting a model where the stimulus is processed in a series of levels of increasing depth of analysis. Therefore, it is possible to strengthen the memory through the "depth of processing": if new information is connected with that already acquired, if it is emotionally significant, if it is well organized, clear, orderly, easily and quickly it will pass to Long-Term Memory, without the need for repetition, but thanks to its structural characteristics.

\section{5) The theory of working memory by Baddeley \& Hitch [3]}

He developed the working memory model, consisting of a central executive, assigned to the reasoning and decisionmaking and supervision tasks of the other 3 sub-systems: a phonological loop (for the maintenance of auditory information), a visuo-spatial notebook (for the maintenance of visual information) and an episodic buffer (to link the short term with the long term).

\section{Amnesia. Classifications and clinical profiles}

Amnesia is a selective memory disorder, characterized by the inability to recall past experiences and / or to acquire new knowledge; it originates in the limbic system, section of the brain (composed of a series of parts including the hippocampus, the amygdala, the hypothalamus etc.), which among its functions has that of maintaining memory. This function is made up of three phases:

a) continuously record events and experiences;

b) encode the information received;

c) recover the archived information.

\section{There are various types of amnesia}

\section{1) Selective differentiation}

a) retrograde amnesia, or loss of memory for events that happened before the cause, but complete lucidity for everything that happened afterwards;

b) antegrade amnesia, or memory loss that does not compromise past memories, but greatly limits the individual's ability to store new information; c) global amnesia, or concerning both aspects mentioned above. Global amnesia is usually associated with bilateral diencephalic or temporal mesial lesions. Unilateral injuries rarely produce amnesia, and in this case the damage affects the left hemisphere more frequently, i.e. the dominant hemisphere for language. Left medial temporal lesions, or more rarely, left thalamic lesions can cause amnesia. Given the dominant role of language in information processing processes, it is possible that the contribution of verbal processes in memory functions is still more important. Unilateral lesions on the left side, although rarely causing global amnesia, can nevertheless cause mild memory deficits, not immediately noticeable. The left temporal lesions selectively compromise the learning and retention of verbal material, even in the absence of aphasic disorders, but not that of visual-spatial stimuli that cannot be verbally coded. Right temporal lesions, on the contrary, leave the long-term verbal memory intact, while interfering with the memorization of visual stimuli and spatial localizations, which are difficult to verbalize. This hemispheric asymmetry (left / verbal, right / visuospatial) is also present in the case of lesions of the dorsomedial nucleus of the thalamus. Also in these cases the deficit is selective for long-term memory, while the short-term span, both verbal and visuospatial is free.

d) lacunar amnesia, or memory loss affecting a specific period of time, which is not remembered by the patient. However, this loss of memory is limited to a few hours or a maximum of days, that is a short period, after the patient does not remember what happened during the previous hours. It is therefore opposed to retrograde amnesia, which instead causes the loss of memory of the patient's entire past;

e) sense-specific amnesia, if it concerns only one sense (for example, agnosia).

\section{2) Temporal differentiation}

a) transient amnesia, as in the case of a traumatic event, with return to normal functionality;

b) stable amnesia, if caused by a serious morbid event (such as cardiac arrest);

c) progressive amnesia, if found in degenerative diseases, which involve the progressive course of the lack of memory.

\section{Neurobiological profiles}

The main neuroanatomical correlates of amnesia are represented by bilateral lesions of two distinct deep areas of the brain: some structures, including the hippocampal region, located in the medial part of the temporal lobe; some nuclei, including the mammillary bodies and the dorso-medial thalamic nucleus, located in the diencephalon. In particular, lesions in the hippocampal area, by surgical resection, 
following vascular infarction or tumor, seem to be directly connected with the mnestic disorders:

a) The amygdala, in particular, however, a medial temporal structure, does not seem to have a primary role in learning but only a relevance for the emotional aspects of learning. Given that the hippocampus holds with the nuclei of the thalamus, with the cingulate cortex and from there with the whole cerebral cortex, its function can be considered both to guarantee the correct registration of the characteristics of the stimulus, the formation of complex associations and the consolidation of the mnestic trace deposited in the cerebral cortex. A lesion of the hippocampus would therefore cause a storage deficit and not a coding and recovery deficit, although some studies do not rule out these hypotheses.

b) Lesions of the mammillary bodies, of the mammillothalamic tracts and of the anterior and dorso-medial nuclei of the thalamus, located on the midline in the diencephalic area, can be associated with amnesia, as in the hypothesis of Korsakoff's syndrome with alcoholic etiology.

c) Lesions of the dorsomedial and anterior nuclei of the thalamus.

d) Lesions of the mammillo-thalamic tracts cause a hippocampal-thalamic disconnection. These lesions affecting the diencephalic structures, and in particular the mammillo-thalamic system, cause amnesia, probably because they prevent an adequate recording of the stimulus, mediated by the sensory information conveyed by the thalamus, damaging the immediate storage function of the simple associations and stimulus information.

e) The turn of the cingulate gyrus an important role in memory processes. Injuries affecting the posterior part of the gyrus girdle cause amnesia, perhaps due to the fact that the destruction of the retrosplenial cortex eliminates a very rich source of projections to the anterior thalamus, which is partially disconnected from the hippocampus. Anterior lesions of the cingulate gyrus, on the other hand, do not cause significant memory disturbances. The fornix is a bundle of white matter that mainly connects the hippocampus with the mammillary bodies: however, its injury does not always cause a memory problem.

f) Lesions affecting the frontal and prefrontal lobes can cause serious memory disturbances, as in the case of herpetic encephalitis (which also interferes with the normal functions of the anterior temporal cortex). In these cases, amnesia is accompanied by serious changes in behavior and personality, anosognosia for the deficit and confabulation. The frontal regions most affected in cases of amnesia are the median and paramedian frontobasal regions: in fact these areas include the septum nuclei, which have important connections with the hippocampus. Frontal syndromes almost always cause a memory disorder. We can find "classic" global amnesia, or milder amnesia, secondary to frontal involvement. In the latter cases, the impairment of executive functions plays a primary role. These functions are used to plan and organize the behavior directed towards a purpose, and to manage all the processing phases of the information. The executive functions therefore have a fundamental role in adopting adequate strategies for memorization, and in finding effective strategies for information retrieval. Attention deficit, and especially attentional supervision, can also seriously compromise the inhibition of irrelevant stimuli, hindering the correct recording of events. Furthermore, amnesia can be caused by lesions that disconnect the Papez circuit, in the medial temporal lobe, between the hippocampus and the diencephalon, the frontal system and the connections between the frontal lobes, and between the thalamus and the basal nuclei. For this reason we can find a memory disorder in numerous dementias.

g) Most patients with auditory-verbal short-term memory impairment have lesions affecting the supramarginal gyrus, located in the posterior lower left parietal region. Some studies have indicated the left supramarginal gyrus as the site of the phonological, and the premotor frontal area (area 44 of Broca) as the site of the articulatory review process, consistently with the hypothesis that this function involves structures that participate in the processes of articulatory programming of spoken language. Other studies have found a correlation between verbal span deficiency and sinister lesions (posterior parietal, fronto-basal associative, and superior temporal). Patients with right parieto-occipital lesions had a reduced visuo-spatial span, confirming the right hemispheric asymmetry in visuo-spatial short-term memory deficits. An activation in the right hemisphere of the visual association cortex (area 19), of the parietal-lower lobule (area 40), and of the prefrontal cortex (area 47) has also been observed with reference to short-term spatial memory: the Associative visual area is involved in the generation of images, the parietal-inferior lobule in the computation of the spatial coordinates, and the prefrontal cortex of the right hemisphere for the retention of information and for the programming of movements towards the target. Finally, left parieto-occipital lesions impair the ability to immediately repeat sequences of verbal and non-verbal visual stimuli. This series of data on the anatomical correlates of visuo-spatial short-term memory deficits confirms the hypothesis of the two systems of processing of visual stimuli proposed by Ungerleider and Mishkin [4-64]: Adeputy visuo-spatial system ("where" system) the retention of information relating to the spatial localization of the stimuli, located in the postero-inferior and frontal parietal association area of the right hemisphere, and a visual system ("what" system) responsible for the retention of verbal and non-visual stimuli, coded as form , located 
in the occipito-parietal associative cortex of the left hemisphere.

\section{Etiopathology and clinical profiles}

a) Amnesia can be caused by

b) Thiamine deficiency, which causes Wernicke's encephalopathy or Korsakoff's disorder) in patients with chronic alcohol abuse or severe hyponutrition;

c) Traumatic brain injury;

d) Convulsions;

e) Anoxia or global cerebral ischemia;

f) Encephalitis;

g) Embolic occlusion on top of the basilar artery, which causes ischemia in the anterior medial temporal lobes;

h) Dementias;

i) Intoxication by various substances (for example, chronic inhalation of solvent, toxicity from amphotericin B or lithium);

j) Hypothalamic tumors;

k) Stress or psychological trauma. Post-traumatic amnesias for the periods immediately preceding and following commotion, or moderate or severe trauma, appear to be due to medial temporal injuries. Moderate or severe traumas can affect larger areas responsible for storing and retrieving information, just as it can occur as a result of various widespread brain diseases that cause dementia;

1) Normal senile aging process. Represents the memory loss that occurs with normal aging. People with benign senile amnesia gradually develop evident memory problems, often initially for names, then for facts and, sometimes, for spatial relationships. Benign senile amnesia is not demonstrably related to dementia, although some aspects of similarity are difficult to ignore. Mild amnesic cognitive impairment may be present in people who have a subjective memory problem, who have worse results on objective memory tests, but who otherwise have intact cognition and function every day. Individuals with mild cognitive impairment are more prone to develop Alzheimer's disease than individuals of the same age who do not have memory problems.

\section{With reference to the diagnostic tests that can be per- formed in the hypothesis of amnesia, we recall}

1) For anterograde amnesia: That which refers to problems encountered in memory for current events and for the learning of new verbal, visuo-spatial information and the events of everyday life ("everyday memory" and "ongoing memory"), a series of tests are used that test long-term memory skills, by learning some verbal or visuospatial information, their retention, and their subsequent re-enactment:

a) Learning a word list: Patients are engaged in tasks that require learning a supra-span word list: this term indicates that the stimuli to remember exceed the normal capacity of the short-term memory span (which usually does not exceed seven). These lists are composed of ten high-frequency lexical bisyllabic words. The patient will then have to repeat all the words he remembers, in the order that come to mind (in the verbal span tests the same presentation order is required), immediately after the presentation, or after a short busy interval (30 or 60 seconds), with non-interfering activity. The list can be repeated a number of times to facilitate learning. In a similar test, the Buschke-Fuld technique, after the first reading of the list, the patient is repeated only the words he has not remembered, up to the criterion of two exact repetitions of the list, or a maximum of eighteen presentations. Subsequently, after an interval of about ten minutes, the patient is asked to recall the list. In a time-delayed recognition task, as in Rey's Verbal Memory Test, the patient, despite not having spontaneously remembered the words, may nevertheless be able to recognize them in the midst of others that act as distractors. Recognition therefore allows us to determine whether the memory trace has been formed, or whether it has decayed completely.

b) Learning pairs of words: A subtest of the Wechsler Memory Scale involves the presentation of pairs of words, some with easy associations, such as "North-South", "flowerrose", others with more difficult associations, such as "starfoot", "wine-bridge". The patient must remember the couple's second word after the presentation of the first. This procedure is repeated three times. Clinical observation is a performance of amnesic patients who are unable to learn difficult associations, even after the third presentation, while instead they perform well in easy couples.

c) Memory of prose: Also this test was conceived for the first time by Wechsler and is contained in the Logical Memory subtest in the WMS. In this test, the patient is first read a short story concerning a fictitious piece of news, then an immediate repetition and a delayed repetition is required after about ten to thirty minutes. The number of items that the patient can remember correctly is recorded.

d) Space supra-span learning: This test measures the capabilities of visuo-spatial long-term memory and uses the same apparatus as the Corsi's Test. The administration procedures are the same as for the verbal supra-span learning test. In this test, the subject must be able to learn an always equal sequence of eight cubes, touched by the examiner on the Corsi tablet, and remember it after an interval of ten minutes.

e) Evidence of Milner's visual labyrinth: In this test, the subject must discover, through various tests and errors, the appropriate "steps" of a path to be followed through a 10 X 10 matrix of bolt heads, which emitted different sounds depending on whether it was the right "passage" or wrong. In this test, patients may be unable to learn and maintain the spatial positions of the bolts that make up the path, or they may also fail to follow and use the rules. Basically in 
both these spatial learning tests, the subjects must memorize a visuospatial pattern consisting of a path that winds through the reference points within a visuo-spatial set.

f) Test of the Complex Figure of Rey: In other famous tests widely used in neuropsychological practice, subjects are required to memorize more or less complex geometric designs. Also in the WMS, one of the subtests (Visual Reproduction), consists in observing some geometric designs, and reproducing them immediately after memory. In Rey's Complex Figure Test and Taylor's analogous test, subjects must first copy a complex geometric design, and then reproduce it from memory after a short interval. These tests are also used to evaluate the constructive spatial capacities of patients, and are therefore sensitive to deficits in visual analysis and perceptual organization. Memory reproduction therefore suffers from the quality of the copy of the drawing made by the patient. However, the memory reproduction test, in the event that the copy test is normal, is a good indicator of the visuo-spatial long-term memory.

2) For anterograde amnesia: Refers to the difficulty of fixing the memories that occurred after the event which caused the mnemonic disorder. In the questionnaires of famous events (or public events) the memory of news stories, TV shows, sporting events is investigated, avoiding the facts whose notoriety transcends the period in which they occurred. For autobiographical episodes, instead, standardized procedures are used, such as structured interviews or tasks in which the patient must produce an autobiographical memory in response to a stimulus word. The patient's answers must obviously be verified with the contribution of a well-informed family member. Furthermore, with simple conditioning techniques, it is possible to evoke conditioned responses in amnesic patients. Usually these subjects do not remember, if not vaguely, the episode of exposure to unconditional stimulus. This shows that, even if at a primitive level of associative response-stimulus learning, the amnesic can consolidate and maintain a simple memory trace in a short time. Amnesic patients seem to be able to learn motor tasks when engaged in motor and kinesthetic skills exercises, such as making a drawing by observing only the hand movements reflected in a mirror, performing a path in a tactile labyrinth, or even maintaining the tip of a stylus in contact with a small metal disc.

3) Material-specific deficits: Which affect verbal or visuospatial information. The short-term retention capacity of stimuli was studied by visually presenting increasing series of verbal stimuli, such as letters or digits, and non-verbal stimuli, such as lines, simple geometric figures, spatial configurations (paths, paths or cell arrays), and through tasks that required the generation and manipulation of mental images. Subjects with brain lesions of the left hemisphere have poor performance in an immediate repetition task of verbal and non-verbal visual stimuli: their short-term memory span was lower than normal subjects. Furthermore, numerous cases of focal brain injury patients with selective immediate memory deficits for verbal material, such as numbers, letters, words, presented audibly have been described. These patients had a reduced auditoryverbal span, while performance improved if the stimulus series was presented visually. However, the deficit was not attributable to acoustic-phonological coding problems. If on the other hand, performance improves with a non-verbal response, then the verbal short-term memory deficit can be attributed to disorders of the verbal production systems. The vast majority of patients with auditory-verbal span deficiency perform better with material presented visually, unlike normal subjects who perform better in auditory modality. This observation suggests that the compromised system in patients is not super-modal but can be divided into two: an auditoryverbal (phonological), and a visual-verbal one.

Finally, with reference to clinical treatment for patients with memory disorders, it is obvious that any underlying pathology or psychological cause of amnesia must be treated. However, some patients with acute amnesia improve spontaneously, while the forms resulting from dementia are more difficult to manage and resolve. Cholinergic drugs in this sense may slightly and temporarily improve memory in patients with Alzheimer's disease, but it is necessary to evaluate case by case, to avoid unnecessary and dangerous drug interactions.

\section{Conclusions}

It is evident that the resolution of the amnestic condition depends mainly on the clinical cause that originates it and therefore on its management and recovery. Amnesia is therefore a symptom of a more extensive pathological condition, which must be investigated and treated with the best possible techniques, except for the hypotheses of irreparable damage.

\section{References}

1. Atkinson K, Shiffrin R (1968) Human memory: a proposed system and its control procesess. In Spencer $\mathrm{K}$, The psychology of learning and motivation: advances in research and theory 2: 89-195. Link: https://bit.ly/2Chq46H

2. Craik F, Lockhart R (1972) Levels of processing: a framework for memory research. Journal of Verbal Learning and Verbal Behaviour 11: 671-684.

3. Baddeley A, Papagno C, Vallar G (1988) When long-term learning depends on short-term storage. Journal of Memory and Language 27: 586-595. Link: https://bit.ly/2YGU7Mt

4. Ungerleider L, Mishkin M (1982) Two cortical visual systems. In Ingle D, Goodale M, Mansfield R, in Analysis of visual behaviour. M.I.T. Press, Cambridge.

5. Baddeley A, Warrington E (1970) Amnesia and the distinction between long and short-term memory. Journal of Verbal Learning and Verbal Behaviour 9 176-189. Link: https://bit.ly/2BknsUQ

6. Baddeley A, Wilson B (1980) Frontal amnesia and the dysexecutive syndrome. Brain Cogn 7: 212-230.

7. Baddeley A (1982) Amnesia: a minimal model and an interpretation. In Cermak L., Human memory and amnesia. Erlbaum, Hillsdale, $\mathrm{NJ}$.

8. Baddeley A (1982) Implications of neuropsychological evidence for theories of normal memory. Philosophical Transaction of te Royal Society 298: 59-72. Link: https://bit.ly/2N8jNMB

9. Baddeley AD, Warrington EK (1973) Memory coding and amnesia Neuropsychologia 11: 159-165. Link: https://bit.ly/3dbEUbo

10. Buschke H, Fuld P (1974) Evaluation storage, retention, and retrieval in disordered memory and learning. Neurology 11: 1019-1025. Link: https://bit.ly/2N31F6U 
11. Cohen N, Squire $L$ (1980) Preserved learning and retention of pattern-analyzing skill in amnesia: dissociation of knowin how and knowing that. Science 210: 207-210. Link: https://bit.ly/3hEGBI9

12. Cohen N, Squire $L$ (1981) Retrograde amnesia and remote memory impairment. Neuropsychologia 19: 337-356. Link: https://bit.ly/2BcvQWC

13. Corkin S (1968) Acquisition of motor skill after bilateral medial temporal lobe excision. Neuropsychologia 6: 255-265. Link: https://bit.ly/2YLYztx

14. Corkin S (1984) Lasting consequences of bilateral medial temporal lobectomy: clinical course and experimental findings in H.M. Semin Neurol 4: 249-259. Link: https://bit.ly/30WAEud

15. De Renzi E, Nichelli P (1975) Verbal and non-verbal short term memory impairment following hemispheric damage. Cortex 11: 341-354. Link: https://bit.ly/2N515Wr

16. De Renzi E, Faglioni P, Ruggerini C (1977) Prove di memoria verbale di impiego clinico per la diagnosi di amnesia. Archivio di Psicologia, Neurologia, Psichiatria 38: 303-318.

17. Galton F (1879) Psychometric experiments. In Brain 2: 149-162.

18. Huppert F, Piercy M (1979) Normal and abnormal forgetting in organic amnesia: effect of locus of lesion. Cortex 15: 385-390. Link: https://bit.ly/3fwwXzd

19. Jonides J, Smith EE, Koeppe RA, Awh E, Minoshima S, et al. (1993) Spatial working memory in humans as revealed by PET. Nature 17: 623-625. Link: https://bit.ly/2N2a1f8

20. Kimura D (1963) Right temporal lobe damage. Archives of Neurology 8: 48-55. Link: https://bit.ly/2YLutGj

21. Langer KG (2019) Early History of Amnesia. Front Neurol Neurosci 44: 64-74. Link: https://bit.ly/3e9QuW5

22. Mayes A, Meudell P, Neary D (1983) Do amnesics adopt inefficient encoding strategies with faces and random shapes. Neuropsychologia 18: 527-540. Link: https://bit.ly/3eawMJJ

23. Mayes A, Meudell P, Pickering A (1985) Is organic amnesia caused by selective deficits in remembering contextual informations? Cortex 21: 167-202. Link: https://bit.ly/2N4POVX

24. Milner B (1965) Visually-guided maze learning in man: effects of bimlatera hippocampal, bilateral frontal and unilateral cerebral lesions. Neuropsychologia 3: 317-339. Link: https://bit.ly/3d9ux84

25. Milner B (1971) Interemispheric differences in the localization of psychological process in man. Br Med Bull 27: 272-277. Link: https://bit.ly/30Qqqvi

26. Milner B, Corkin S, Teuber HL (1968) Further analysis of the hippocampa amnesic syndrome: a 14 year follow-up study of H.M. Neuropsychologia 6 : 215-234. Link: https://bit.ly/2UPcjlR

27. Milner B, Teuber J (1968) Alteration of perception and memory in man: reflections on methods. In Weiskrantz, L. (a cura di), Analysis of behavioral change. Harper \& Row, New York.

28. Novelli G, Papagno C, Capitani E, Laiacona M, Cappa SF, et al. (1986) Tre test clinici di memoria verbale a lungo termine. Archivio di Psicologia, Neurologia e Psichiatria 47: 278-296.

29. Papez J (1937) A proposed mechanism of emotion. Archives of Neurology and Psychiatry 38: 725-743. Link: https://bit.ly/30SgEc6

30. Perani D, Bressi S, Cappa SF, Vallar G, Alberoni M,et al, (1993) Evidence of multiple memory systems in the human brain: a (18F) FDG PET metabolic study. Brain 116: 903-919. Link: https://bit.ly/2N8ox4R

31. Perrotta G (2019) Psicologia clinica. Luxco ed., I ed.
32. Perrotta G (2019) Psicologia dinamica. Luxco ed., I ed.

33. Perrotta G (2019) Psicologia generale. Luxco ed., I ed.

34. Perrotta G (2019) Anxiety disorders: definitions, contexts, neural correlates and strategic therapy. J Neur Neurosci 6: 046. Link: https://bit.ly/2ZpWNQG

35. Perrotta G (2019) Post-traumatic stress disorder: Definition, contexts, neura correlations and cognitive-behavioral therapy. J Pub Health Nutr 2: 40-47. Link: https://bit.ly/2WMQCo1

36. Perrotta G (2019) Sleep-wake disorders: Definition, contexts and neural correlations. J Neurol Psychol 3: 9. Link: https://bit.ly/2AJjBAX

37. Perrotta G (2019) Depressive disorders: Definitions, contexts, differential diagnosis, neural correlates and clinical strategies. Peertechz Arch Depress Anxiety 5: 009-033. Link: https://bit.ly/2Y7BtOI

38. Perrotta G (2019) Executive functions: definition, contexts and neuropsychological profiles. J Neuroscience Neurological Surgery 4: 4-77.

39. Perrotta G (2019) Alzheimer's disease: definition, contexts, neural correlates, strategies and clinical approaches. J Aging Stud Ther 1. Link: https://bit.ly/30N2ZD3

40. Perrotta G (2019) Attention Deficit Hyperactivity Disorder: definition contexts, neural correlates and clinical strategies. J Addi Adol Behav 2. Link: https://bit.ly/2UTnvOC

41. Perrotta G (2020) Human mechanisms of psychological defence: definition, historical and psychodynamic contexts, classifications and clinical profiles. Int J Neurorehabilitation Eng 7: 1. Link: https://bit.ly/3e8Vpq4

42. Perrotta G (2020) General overview of "human dementia diseases" definitions, classifications, neurobiological profiles and clinical treatments. Journal of Gerontology \& Geriatrics Studies, Gerontol \& Geriatric stud 6. Link: https://bit.ly/30Tnk9l

43. Pizzamiglio L, Laicardi C, Lisi F (1979) Questionario di memoria di event remoti. Giornale Italiano di Psicologia 1: 127-148

44. Rey A (1968) Reattivo della figura complessa. Organizzazioni Speciali, Firenze.

45. Ruggeri M (2014) Le amnesie e i processi patologici della memoria, C.A.R. Roma.

46. Sanders H, Warrington E (1975) Retrograde amnesia in organic amnesic patient. Cortex 11: 397-400. Link: https://bit.ly/2NiMpDf

47. Shallice T, Vallar G (1990) The impairment of auditory verbal short term storage. In Vallar G \& Shallice T, Neuropsychological impairments of short-term memory. Cambridge University Press, Cambridge. Link: https://bit.ly/37F0yDK

48. Spinnler H, Tognoni G (1987) Standardizzazione italiana di tests neuropsicologici. Italian Journal of Neurological Sciences. Link: https://bit.ly/2Cj07C5

49. Thompson R (1992) Memory. Current Opinion in Neurobiology 2: 203-208.

50. Vallar G, Papagno C (1995) Neuropsychological impairments of short-term memory. In Baddeley A, Wilson B, Watts F, in Handbook of memory disorders, 135-165. John Wiley \& Sons, Chichester. Link: https://bit.ly/2YKdqEQ

51. Warrington E, James M (1967) Tachistoscopic number estimation in patients with unilateral cerebral lesions. J Neurol Neurosurg Psychiatry 3: 468-474. Link: https://bit.ly/37JeMUj

52. Warrington $E$, Weiskrantz $L$ (1968) A study of learning and retention in amnesic patients. Neuropsychologia 6: 283-291. Link: https://bit.ly/2N5Kvph

53. Warrington EK, Weiskrantz L (1970) Amnesic syndrome: consolidation or retrieval?. Nature 228: 628-630. Link: https://go.nature.com/3fsHZW4

Citation: Perrotta G (2020) Amnesia: Definition, main models, classifications, neurobiological profiles and clinical treatments. Arch Depress Anxiety 6(1): 037-044. DOI: https://dx.doi.org/10.17352/2455-5460.000050 
54. Warrington E, Rabin P (1971) Visual span of apprehension in patients with unilateral cerebral lesions Q J Exp Psychol 23: 423-431. Link: https://bit.ly/2AJ14Vr

55. Warrington E, Weiskrantz $L$ (1973) An analysis of short-term and long-term memory defects in man. In Deutsch, J. The physiological basis of memory. Academic Press, NY.

56. Warrington EK, Weiskrantz L (1971) Amnesia: a disconnection syndrome? Neuropsychologia 20: 233-248.

57. Warrington E, McCarthy $R$ (1988) The fractionation of retrograde amnesia Brain and Cognition 7: 184-200. Link: https://bit.ly/2BfmFEY

58. Wechsler D (1945) A standardized memory scale for clinical use. Journal of Psychology 19: 87-95. Link: https://bit.ly/2YPdnHY

59. Wechsler D (1974) Scala di intelligenza per adulti. Organizzazioni Speciali, Firenze.
60. Wechsler D (1981) Wechsler Memory Scale. Forma I. Organizzazioni Speciali, Firenze.

61. Wechsler D, Stone CP (1985) Wechsler Memory Scale. Forma II. Organizzazioni Speciali, Firenze.

62. Weiskrantz L, Warrington EK (1979) Conditioning in amnesic patients. Neuropsychologia 17: 187-194. Link: https://bit.ly/2YKfbBW

63. Wickelgren W (1979) Chunking and consolidation: a theoretical synthesis of semantic networks, configuring in conditioning, S-R versus cognitive learning, normal forgetting, the amnesic syndrome, and the hippocampal arousal system. Psychological Review 86: 44-60. Link: https://bit.ly/2YHI95t

64. Wilson BA (1987) Rehabilitation of memory. The Guilford Press, NY 250. Link: https://bit.ly/2YaiqTX

\section{Discover a bigger Impact and Visibility of your article publication with}

\section{Peertechz Publications}

\section{Highlights}

* Signatory publisher of ORCID

* Signatory Publisher of DORA (San Francisco Declaration on Research Assessment)

* Articles archived in worlds' renowned service providers such as Portico, CNKI, AGRIS, TDNet, Base (Bielefeld University Library), CrossRef, Scilit, J-Gate etc.

* Journals indexed in ICMJE, SHERPA/ROMEO, Google Scholar etc.

* OAI-PMH (Open Archives Initiative Protocol for Metadata Harvesting)

* Dedicated Editorial Board for every journa

* Accurate and rapid peer-review process

* Increased citations of published articles through promotions

* Reduced timeline for article publication

Submit your articles and experience a new surge in publication services (https://www.peertechz.com/submission).

Peertechz journals wishes everlasting success in your every endeavours.

Copyright: () 2020 Perrotta G. This is an open-access article distributed under the terms of the Creative Commons Attribution License, which permits unrestricted use, distribution, and reproduction in any medium, provided the original author and source are credited. 